\title{
The Study of Lighting Quality of LED and HPS Luminaires Based on Various Road Surface Properties
}

\author{
Suntiti Yoomak, and Atthapol Ngaopitakkul \\ Faculty of Engineering King Mongkut's Institute of Technology Ladkrabang Bangkok, Thailand
}

\begin{abstract}
This paper presents analysis of lighting quality in different road surface conditions using the DIALux software. Dry and wet road surfaces are used to study lighting quality by following classifications of the International Commission on Illumination (CIE). Lighting quality of high pressure sodium (HPS) and light emitting diode (LED) luminaires are compared, based on roadway with a traffic island. Results indicate that the HPS luminaire can provide better average illuminance and average luminance values than the LED luminaire, resulting in positive visual performance. However, the LED luminaire can achieve visual and comfort performance including energy saving due to its light distribution efficiency. For lighting quality on different road surface conditions, the lighter dry road surface materials, the higher lighting quality. Wet road surfaces cause very bright areas on road surface alternating with large dark areas. It results in the average luminance of the surface increased while overall uniformity decreased.
\end{abstract}

\section{Introduction}

The important role of road lighting systems is visibility maintenance of road users at the night time equal to the daytime. However, recently the road lighting systems not only extract visual information to detection of people, automobiles and another object, but also help to decrease the number of accidents and crime rates [1]. The properties of road surfaces are correlated with the parameters of luminance and uniformity. Therefore, change of road surface properties leads to difference in brightness.

Reflection properties change cause wearing and different weather conditions. Road surfaces are classified into classes with their specular factor $\mathrm{S} 1$ value, which is determined according to the CIE [2]. Schreuder [3] investigates road surfaces properties in roadway of the Netherlands. Results show that drainage asphalt surfaces normally used on highways are not satisfied for the CIE standard. However, coarse dense asphalt surface that have been used for decades still meet the CIE standard. Moretti et al. [4] claims that the lighter colour of a road surface is better visibility for drivers. In addition, it gives a reduction in power consumption needed to achieve the minimum illumination requirements in comparison to conventional road surfaces i.e. asphalt pavements. Dawei et al. [5] study the effects various composition factors on the resistance of road surfaces and validate the performance of a selected road surface. Then, they [6] investigate the impact of road surfaces to use in road surface design and aggregate selection. In Thailand, the Department of Highways is responsible for roadway construction. An aggregate of cement or asphalt surfaces is primarily used to make the roadway [7], leading to road surface properties complying well with the CIE standard.

There are several papers, comparing with HPS and LED luminaire. Rodrigues et al. [8] indicate that HPS luminaires are better illuminance values than LED luminaires as the former consume twice power of the latter. However, the LED luminaires enjoy considerable advantages in terms of color sensation, color rendering, and energy saving. Sędziwy et al. [9] study different aspects of roadway lighting energy efficiency using LED technology and smart lighting systems. The results claim that replacement of HPS luminaires with LED luminaires can save energy of $31 \%$ with and $66 \%$ for improved technology in the future.

In this paper, roadway lighting quality from comparing between HPS and LED luminaires, including dry and wet road surface conditions based on R and W classes of the CIE are analyzed. Main roadways with a traffic island (opposite, staggered, and twin-central arrangements) are carried out a study. The DIALux software is used to calculate road lighting parameters, namely average illuminance, average luminance, overall uniformity, and threshold incremental.

\section{Roadway lighting simulation design}

In this paper, roadway lighting simulation using the DIALux software in order to analyze lighting quality in different road surface conditions is presented. Dry and wet road surfaces are used to study lighting quality. Dry and wet road surface properties are described by the $\mathrm{R}$ and $\mathrm{W}$ classification systems respectively defined by the CIE [10]-[11] as shown in Table 1. 
Table 1. Classification systems for dry road surface classes $R$ and a wet road surface class W [10]-[11]

\begin{tabular}{|c|c|c|c|}
\hline Conditions & $\begin{array}{c}\text { Class } \\
\text { standard }\end{array}$ & Class limits & $\begin{array}{c}\text { Standard } \\
\text { Q0 }\end{array}$ \\
\hline \multirow{4}{*}{ Dry } & $\mathrm{R} 1$ & $\mathrm{~S} 1<0.42$ & 0.10 \\
\cline { 2 - 4 } & $\mathrm{R} 2$ & $\begin{array}{c}0.42 \leq \mathrm{S} 1< \\
0.85\end{array}$ & 0.07 \\
\cline { 2 - 4 } & $\mathrm{R} 3$ & $\begin{array}{c}0.85 \leq \mathrm{S} 1< \\
1.35\end{array}$ & 0.07 \\
\cline { 2 - 4 } & $\mathrm{R} 4$ & $1.35 \leq \mathrm{S} 1$ & 0.08 \\
\hline \multirow{6}{*}{ Wet } & $\mathrm{W} 1$ & $\mathrm{~S} 1<4.5$ & 0.114 \\
\cline { 2 - 4 } & $\mathrm{W} 2$ & $4.5 \leq \mathrm{S} 1<7.2$ & 0.15 \\
\cline { 2 - 4 } & $\mathrm{W} 3$ & $7.2 \leq \mathrm{S} 1<9.8$ & 0.196 \\
\cline { 2 - 4 } & $\mathrm{W} 4$ & $9.8 \leq \mathrm{S} 1<12.0$ & 0.247 \\
\hline \multirow{7}{*}{} & & &
\end{tabular}

For the simulation, a main roadway lighting system that has a moderate traffic volume (M2): average illuminance $($ Eav) $\geq 21.5$ lux, average luminance (Lav) $\geq$ $1.5 \mathrm{~cd} / \mathrm{m} 2$, overall uniformity (U0) $\geq 0.4$, threshold incremental $(\mathrm{TI}) \leq 10 \%$, and street lighting energy efficiency criterion (SLEEC) $\leq 1 \mathrm{~W} /(\mathrm{cd} / \mathrm{m} 2 * \mathrm{~m} 2)$ is selected. In Thailand, there is the pilot project of Provincial Electricity Authority (PEA) to improve energy efficient roadway lighting systems, which is

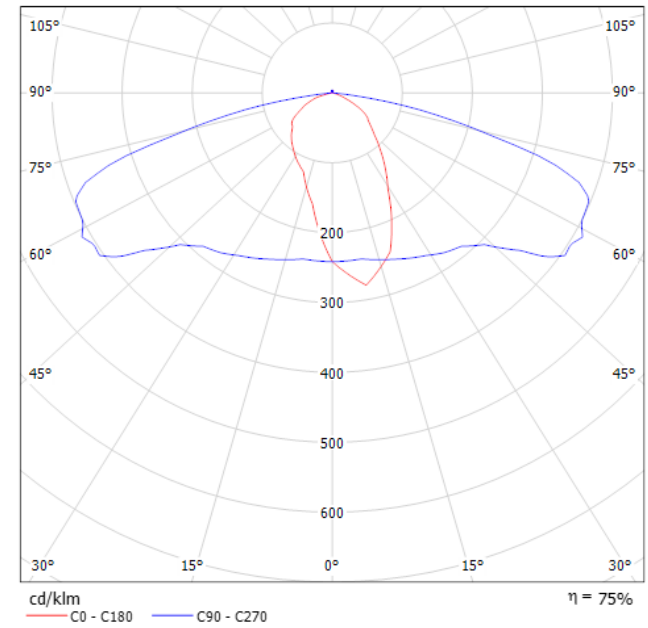

(a) 250-W HPS luminaire
"Mainstreaming Energy Efficiency in Thai Municipalities". The scope of work is 250-watt HPS luminaire replacement with a 120-watt LED for 100 luminaires on the roadway requiring the illuminaice value of 21.5 lux. According to Term of Reference (TOR) of PEA, LED luminaires used must have qualify as rated input of lower 150 watts and efficiency more than 90 lumens per watt [12]. For this reason, the luminaire used are high pressure sodium (HPS) luminaires with $250 \mathrm{~W}$ $(32,000$ lumens) and light emitting diode (LED) luminaires with $120 \mathrm{~W}(12,110$ lumens $)$ which are actually installed on the main roadway of Thailand. The luminous intensity distribution curves of these luminaires are depicted in Fig. 1.

Components of roadway lighting pole used for simulation illustrate in Fig. 2. Boom length, boom angle, overhang, and mounting height are assigned to have 2.5 $\mathrm{m}$ boom length, $15^{\circ}$ boom angle, $1.5 \mathrm{~m}$ overhang, and 9 $\mathrm{m}$ mounting height, which are standard installations of main roadways in Thailand, for investigating lighting quality. Thank to road width and pole arrangements directly affecting roadway lighting quality and energy consumption, the main roadway lighting system that have a moderate traffic volume (M2) is employed to set 0.67 maintenance factors.

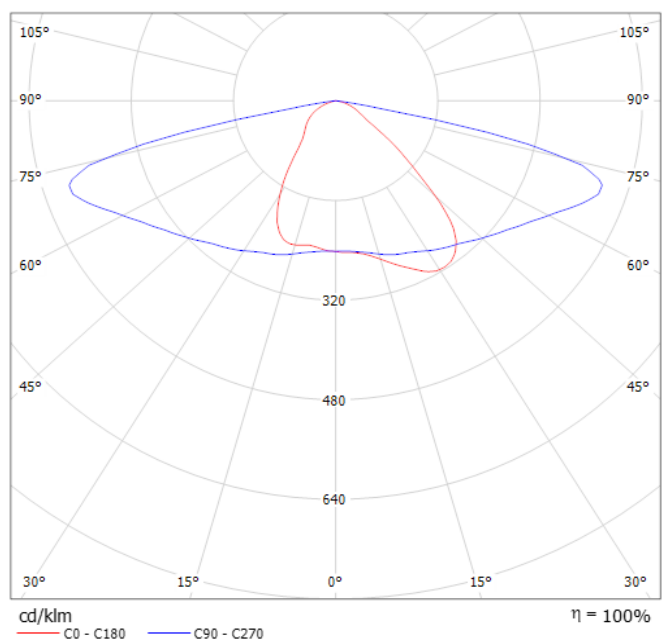

(b) 120-W LED luminaire

Fig. 1. luminous intensity distribution curves

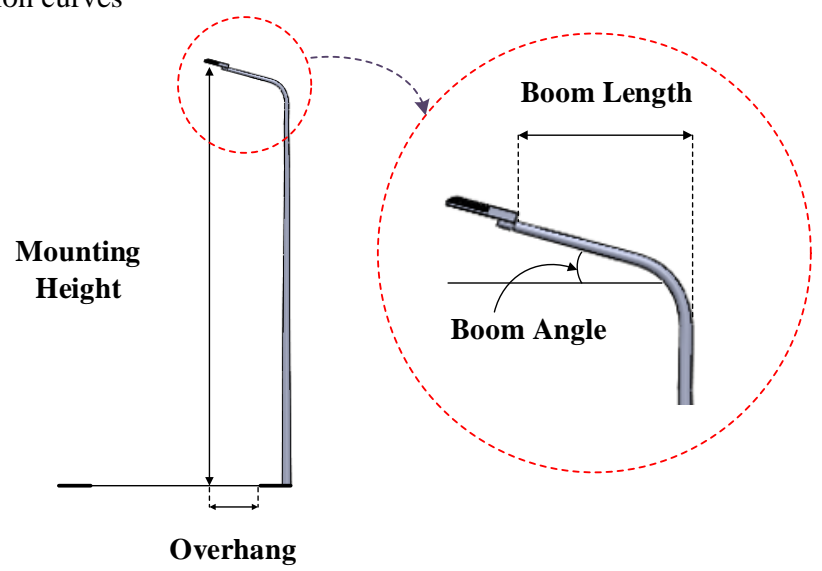

Fig. 2. components of a roadway lighting pole 


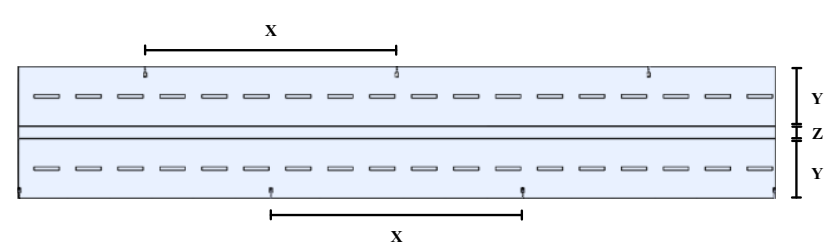

(a) Outline of a roadway

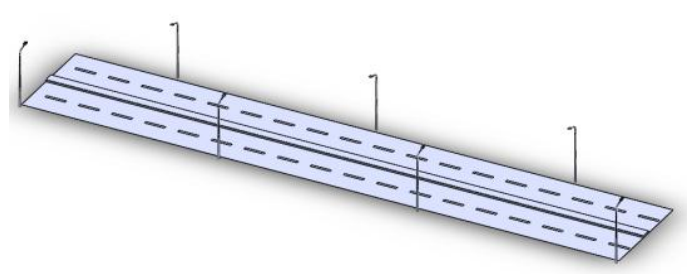

(c) A staggered arrangement

Fig. 3. Simulation model of roadway with a traffic island

The model of roadway with a traffic island for the simulation shows in Fig. 3. In Fig. 3(a), the simulation is made for a dual carriageway: each carriageway is $7 \mathrm{~m}$ width with two lanes denoted by $\mathrm{Y}$ and thus a lane is 3.5 $\mathrm{m}$ width, luminaire spacing $(\mathrm{X})$ with $36 \mathrm{~m}$, and traffic island width $(\mathrm{Z})$ with $1.5 \mathrm{~m}$. In this case study, we propose three basic pole arrangements. As shown Fig. 3(b)-3(d), there are: the opposite, the staggered, and the twin-central arrangement.

\section{Simulation results}

This section presents results of roadway lighting simulations using the DIALux program. HPS luminaires and LED luminaires are compared for the analysis of roadway lighting quality with different road surfaces, dry road surfaces (classes R1, R2, R3, and R4) and wet road surfaces (classes W1, W2, W3, and W4). The simulations are carried out on roadway lighting with a traffic island comprising opposite, staggered and twin-central arrangements.

In order to study and analyze of lighting quality, roadways with a traffic island, a dual carriageway with four lanes, are set to have $14 \mathrm{~m}$ road width, $9 \mathrm{~m}$ mounting height, and $36 \mathrm{~m}$ luminaire spacing, which are normal installations of main roadways in Thailand. Simulation results are compared in terms of lighting quality of HPS and LED luminaires in the same condition. For lighting quality investigation, the following parameters are used: average illuminance (Eav), average luminance (Lav), overall uniformity $\left(\mathrm{U}_{0}\right)$, threshold increment (TI), and street lighting energy efficiency criterion (SLEEC).

Table. 2 shows that the opposite and staggered arrangements can give more Eav and Lav values than the twin central arrangement, since low brightness mostly occurs among area between pole spacing of the twin central arrangement. For this reason, the opposite and staggered arrangements have more SLEEC values than

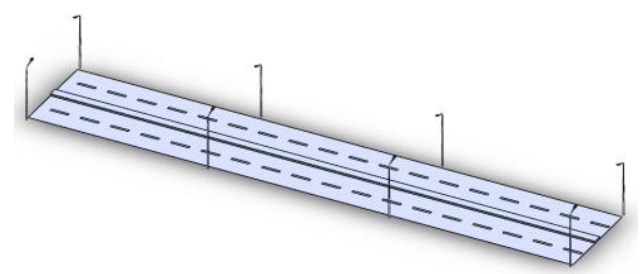

(b) An opposite arrangement

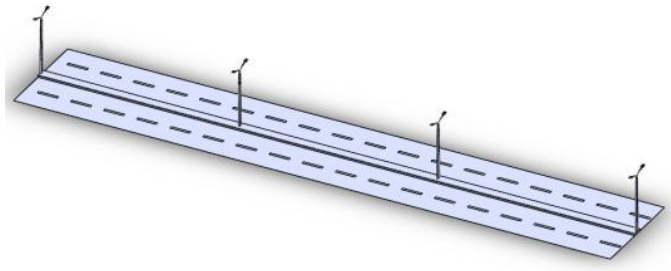

(d) A twin-central arrangement

twin central arrangements, hence energy efficiency. $U_{0}$ and TI values are fairly not different for all types of pole arrangements. However, the $\mathrm{E}_{\mathrm{av}}$ values do not change. HPS luminaires generate higher luminous flux than LED luminaires. Therefore, using HPS luminaires can provide more $E_{a v}$ and $L_{a v}$ values than the other one. However, light distribution characteristics of the LED luminaires which can effectively control the amount of light falling on road surface have a positive effect on $\mathrm{U}_{\mathrm{o}}$ and TI, and SLEEC values.

The simulation results of HPS and LED luminaires on dry road surface class $\mathrm{R} 1$ show the best $\mathrm{L}_{\mathrm{av}}$ values as there is the highest average luminance coefficient $Q_{0}$, leading to better SLEEC values than other road surfaces. Owing to low specular factor $\mathrm{S} 1, \mathrm{U}_{\mathrm{o}}$ values are well satisfied. For this reason, R1 road surface is low diffuse and shiny surfaces, hence low TI values when comparing with another a road surface. By comparing with the standard, HPS luminaires can give lighting quality values meet the standard except the opposite arrangement that shows slightly higher TI values. For LED luminaires, the opposite and staggered arrangements can be acceptable for the standard, while the twin central arrangements have lighting quality values, $\mathrm{L}_{\mathrm{av}}$, lower than the standard.

Lighting quality of dry road surface classes R2 and $\mathrm{R} 3$ provides lower $\mathrm{L}_{\mathrm{a}}$ values and higher TL values than the road surface class $\mathrm{R} 1$ due to lower the average luminance coefficient $\mathrm{Q}_{0}$ value. In addition, the $\mathrm{U}_{\mathrm{o}}$ values of them decrease caused by high diffuse and shiny road surfaces. In case of dry road surface class R2, all pole arranges of HPS luminaires have almost the lighting quality values satisfied the standard except the TI values. For LED luminaires, the twin central arrangements are unsuitable due to low lighting quality. Next, for dry road surface class R3, HPS luminaires give higher the TI values than the standard for the all arrangements. For LED luminaires, it is found that the $\mathrm{L}_{\mathrm{av}}$ values are lower than the standard for entire arrangements. 
Table 2. The results of roadway lighting simulations on road with a traffic island in cases of dry road surface

\begin{tabular}{|c|c|c|c|c|c|c|c|c|}
\hline \multirow{2}{*}{ Classes } & \multirow{2}{*}{ Parameters } & \multirow{2}{*}{ Standard } & \multicolumn{3}{|c|}{ HPS luminaire } & \multicolumn{3}{|c|}{ LED luminaire } \\
\hline & & & Opposite & Staggered & Twin central & Opposite & Staggered & Twin central \\
\hline \multirow{5}{*}{ R1 } & $\mathrm{E}_{\mathrm{av}}(\mathrm{lux})$ & $\geq 21.5$ & 43 & 43 & 37 & 23 & 23 & 16 \\
\hline & $\mathrm{L}_{\mathrm{av}}\left(\mathrm{cd} / \mathrm{m}^{2}\right)$ & $\geq 1.5$ & 4.17 & 4.17 & 3.47 & 2.20 & 2.21 & 1.44 \\
\hline & $\mathrm{U}_{\mathrm{o}}$ & $\geq 0.4$ & 0.55 & 0.60 & 0.65 & 0.69 & 0.65 & 0.56 \\
\hline & TI $(\%)$ & $\leq 10$ & 11 & 9 & 10 & 9 & 7 & 9 \\
\hline & $\begin{array}{c}\text { SLEEC } \\
\left(\mathrm{W} /\left(\mathrm{cd} / \mathrm{m}^{2} * \mathrm{~m}^{2}\right)\right)\end{array}$ & $\leq 1$ & 0.25 & 0.25 & 0.30 & 0.20 & 0.20 & 0.30 \\
\hline \multirow{5}{*}{$\mathrm{R} 2$} & $\mathrm{E}_{\mathrm{av}}(\operatorname{lux})$ & $\geq 21.5$ & 43 & 43 & 37 & 23 & 23 & 16 \\
\hline & $\mathrm{L}_{\mathrm{av}}\left(\mathrm{cd} / \mathrm{m}^{2}\right)$ & $\geq 1.5$ & 2.97 & 2.96 & 2.57 & 1.54 & 1.54 & 1.08 \\
\hline & $\mathrm{U}_{\mathrm{o}}$ & $\geq 0.4$ & 0.62 & 0.57 & 0.74 & 0.70 & 0.69 & 0.58 \\
\hline & TI $(\%)$ & $\leq 10$ & 14 & 12 & 12 & 12 & 9 & 11 \\
\hline & $\begin{array}{c}\text { SLEEC } \\
\left(\mathrm{W} /\left(\mathrm{cd} / \mathrm{m}^{2} * \mathrm{~m}^{2}\right)\right)\end{array}$ & $\leq 1$ & 0.35 & 0.35 & 0.40 & 0.28 & 0.28 & 0.40 \\
\hline \multirow{5}{*}{$\mathrm{R} 3$} & $\mathrm{E}_{\mathrm{av}}(\operatorname{lux})$ & $\geq 21.5$ & 43 & 43 & 37 & 23 & 23 & 16 \\
\hline & $\mathrm{L}_{\mathrm{av}}\left(\mathrm{cd} / \mathrm{m}^{2}\right)$ & $\geq 1.5$ & 2.82 & 2.82 & 2.47 & 1.45 & 1.45 & 1.04 \\
\hline & $\mathrm{U}_{\mathrm{o}}$ & $\geq 0.4$ & 0.58 & 0.56 & 0.70 & 0.65 & 0.67 & 0.56 \\
\hline & TI $(\%)$ & $\leq 10$ & 14 & 12 & 12 & 13 & 10 & 11 \\
\hline & $\begin{array}{c}\text { SLEEC } \\
\left(\mathrm{W} /\left(\mathrm{cd} / \mathrm{m}^{2 *} \mathrm{~m}^{2}\right)\right)\end{array}$ & $\leq 1$ & 0.37 & 0.37 & 0.42 & 0.30 & 0.30 & 0.41 \\
\hline \multirow{5}{*}{$\mathrm{R} 4$} & $\mathrm{E}_{\mathrm{av}}(\operatorname{lux})$ & $\geq 21.5$ & 43 & 43 & 37 & 23 & 23 & 16 \\
\hline & $\mathrm{L}_{\mathrm{av}}\left(\mathrm{cd} / \mathrm{m}^{2}\right)$ & $\geq 1.5$ & 2.99 & 2.99 & 2.68 & 1.51 & 1.51 & 1.12 \\
\hline & $\mathrm{U}_{\mathrm{o}}$ & $\geq 0.4$ & 0.55 & 0.52 & 0.60 & 0.60 & 0.61 & 0.54 \\
\hline & TI $(\%)$ & $\leq 10$ & 14 & 11 & 11 & 12 & 9 & 10 \\
\hline & $\begin{array}{c}\text { SLEEC } \\
\left(\mathrm{W} /\left(\mathrm{cd} / \mathrm{m}^{2} * \mathrm{~m}^{2}\right)\right)\end{array}$ & $\leq 1$ & 0.35 & 0.35 & 0.39 & 0.28 & 0.28 & 0.38 \\
\hline
\end{tabular}

Table 3. The results of roadway lighting simulations on road with a traffic island in cases of wet road surface

\begin{tabular}{|c|c|c|c|c|c|c|c|c|}
\hline \multirow{2}{*}{ Classes } & \multirow{2}{*}{ Parameters } & \multirow{2}{*}{ Standard } & \multicolumn{3}{|c|}{ HPS luminaire } & \multicolumn{3}{|c|}{ LED luminaire } \\
\hline & & & Opposite & Staggered & Twin central & Opposite & Staggered & Twin central \\
\hline \multirow{5}{*}{ W1 } & $\mathrm{E}_{\mathrm{av}}(\operatorname{lux})$ & $\geq 21.5$ & 43 & 43 & 37 & 23 & 23 & 16 \\
\hline & $\mathrm{L}_{\mathrm{av}}\left(\mathrm{cd} / \mathrm{m}^{2}\right)$ & $\geq 1.5$ & 5.07 & 5.09 & 4.94 & 2.51 & 2.52 & 2.14 \\
\hline & $\mathrm{U}_{\mathrm{o}}$ & $\geq 0.4$ & 0.47 & 0.43 & 0.45 & 0.51 & 0.51 & 0.40 \\
\hline & TI $(\%)$ & $\leq 10$ & $* /$ & $* /$ & 7 & 8 & 6 & 6 \\
\hline & $\begin{array}{c}\text { SLEEC } \\
\left(\mathrm{W} /\left(\mathrm{cd} / \mathrm{m}^{2} * \mathrm{~m}^{2}\right)\right)\end{array}$ & $\leq 1$ & 0.20 & 0.20 & 0.21 & 0.17 & 0.17 & 0.20 \\
\hline \multirow{5}{*}{ W2 } & $\mathrm{E}_{\mathrm{av}}(\operatorname{lux})$ & $\geq 21.5$ & 43 & 43 & 37 & 23 & 23 & 16 \\
\hline & $\mathrm{L}_{\mathrm{av}}\left(\mathrm{cd} / \mathrm{m}^{2}\right)$ & $\geq 1.5$ & 6.57 & 6.56 & 6.63 & 3.16 & 3.16 & 2.87 \\
\hline & $\mathrm{U}_{\mathrm{o}}$ & $\geq 0.4$ & 0.40 & 0.38 & 0.28 & 0.36 & 0.39 & 0.25 \\
\hline & TI $(\%)$ & $\leq 10$ & $* /$ & $* /$ & $* /$ & 6 & 5 & 5 \\
\hline & $\begin{array}{c}\text { SLEEC } \\
\left(\mathrm{W} /\left(\mathrm{cd} / \mathrm{m}^{2} * \mathrm{~m}^{2}\right)\right)\end{array}$ & $\leq 1$ & 0.16 & 0.16 & 0.16 & 0.14 & 0.14 & 0.15 \\
\hline \multirow{5}{*}{ W3 } & $\mathrm{E}_{\mathrm{av}}(\operatorname{lux})$ & $\geq 21.5$ & 43 & 43 & 37 & 23 & 23 & 16 \\
\hline & $\mathrm{L}_{\mathrm{av}}\left(\mathrm{cd} / \mathrm{m}^{2}\right)$ & $\geq 1.5$ & 8.11 & 8.16 & 8.32 & 3.82 & 3.85 & 3.59 \\
\hline & $\mathrm{U}_{\mathrm{o}}$ & $\geq 0.4$ & 0.28 & 0.30 & 0.19 & 0.27 & 0.27 & 0.17 \\
\hline & TI $(\%)$ & $\leq 10$ & $* /$ & $* /$ & $* /$ & 5 & 4 & 4 \\
\hline & $\begin{array}{c}\text { SLEEC } \\
\left(\mathrm{W} /\left(\mathrm{cd} / \mathrm{m}^{2} * \mathrm{~m}^{2}\right)\right)\end{array}$ & $\leq 1$ & 0.13 & 0.13 & 0.12 & 0.11 & 0.11 & 0.12 \\
\hline \multirow{5}{*}{ W4 } & $\mathrm{E}_{\mathrm{av}}(\operatorname{lux})$ & $\geq 21.5$ & 43 & 43 & 37 & 23 & 23 & 16 \\
\hline & $\mathrm{L}_{\mathrm{av}}\left(\mathrm{cd} / \mathrm{m}^{2}\right)$ & $\geq 1.5$ & 8.47 & 8.46 & 8.83 & 3.88 & 3.87 & 3.73 \\
\hline & $\mathrm{U}_{\mathrm{o}}$ & $\geq 0.4$ & 0.19 & 0.20 & 0.16 & 0.19 & 0.18 & 0.13 \\
\hline & TI $(\%)$ & $\leq 10$ & $* /$ & $* /$ & $* /$ & 5 & 4 & 4 \\
\hline & $\begin{array}{c}\text { SLEEC } \\
\left(\mathrm{W} /\left(\mathrm{cd} / \mathrm{m}^{2} * \mathrm{~m}^{2}\right)\right)\end{array}$ & $\leq 1$ & 0.12 & 0.12 & 0.12 & 0.11 & 0.11 & 0.12 \\
\hline
\end{tabular}

*/ Note that the equation of glare evaluation is valid for $0.05 \mathrm{~cd} / \mathrm{m}^{2}<L_{a v}<5 \mathrm{~cd} / \mathrm{m}^{2}$ according to the CIE 31-1976 [19] 
In dry road surface class $\mathrm{R} 4$, there is lower the average luminance coefficient $\mathrm{Q}_{0}$ value than dry road surface classes R2 and R3. However, the SLEEC values are not somewhat different as the roadway is very wide. The class $\mathrm{R} 4$ has minimum $\mathrm{U}_{\mathrm{o}}$ values as this road surface is the highest specular factor S1. HPS luminaires provide better $L_{a v}$ values than LED luminaires due to its higher luminous flux whereas LED luminaires are better in the $\mathrm{U}_{\mathrm{o}}$ and SLEEC values. However, the lighting quality of both luminaires is unsatisfied except the staggered LED luminaire, since the TI values fall below the standard.

Table 3 shows simulation results of using HPS and LED luminaires on wet road surfaces. It is found that the $E_{a v}$ value does not change when road surface conditions are variable. The lighting quality of opposite, staggered, and twin central arrangements have the similar trend in case of the dry road surface conditions. However, average luminance coefficients $\mathrm{Q}_{0}$ and specular factors $\mathrm{S} 1$ dramatically increase, resulting in the high $L_{a v}$ value and the low $U_{o}$ value. An overview of the lighting quality of the both luminaires indicates that HPS luminaires can give better $\mathrm{E}_{\mathrm{av}}$ and $\mathrm{L}_{\mathrm{av}}$ values than LED luminaires, while $\mathrm{U}_{\mathrm{o}}$ and SLEEC values are rarely different. Additionally, TI values cannot be calculated thank to a restriction on the CIE recommendation.

In wet road surface class $\mathrm{W} 1, \mathrm{~L}_{\mathrm{av}}$ and SLEEC values have a trend to slightly increase comparing with dry road surface class R1. However, in wet road surface conditions, dramatic rises of the specular factor $\mathrm{S} 1$ value have an effect on low $U_{0}$ values. However, the $L_{a v}, U_{0}$, and SLEEC values are still higher than the standard.

For wet road surface classes $\mathrm{W} 2, \mathrm{~W} 3$, and $\mathrm{W} 4$, the average luminance coefficient $\mathrm{Q}_{0}$ and the specular factor $\mathrm{S} 1$ values dramatically increase especially in class W4, resulting in high $\mathrm{L}_{\mathrm{av}}$ and SLEEC values. However, the $\mathrm{U}_{\mathrm{o}}$ values are unusable caused by sharp increase in the specular factor $S 1$ value; observing the $U_{0}$ values of wet road surface classes $\mathrm{W} 2, \mathrm{~W} 3$, and $\mathrm{W} 4$ that decrease respectively. By comparing the lighting quality between LED and HPS luminaires, it is found that HPS luminaires can provide better $L_{a v}$ values than LED luminaires because of their more luminous flux. However, LED luminaires are efficient in term of energy by taken the SLEEC values into the account. Owing to increasingly wide roadway, the $\mathrm{U}_{\mathrm{o}}$ values are hardly different. The both luminaires can give the $\mathrm{E}_{\mathrm{av}}, \mathrm{L}_{\mathrm{av}}$, and SLEEC values to meet the standard except twin central arrangements of the LED luminaires. Unfortunately, wet road surface classes W2, W3, and W4 have not good enough of the $\mathrm{U}_{\mathrm{o}}$ values.

\section{Conclusions}

The simulation results of HPS and LED luminaire in roadway lighting systems with a traffic island in cases of dry and wet road surfaces indicate that the $E_{a v}$ value is not completely different when the characteristics of road surfaces have change, while the road surface properties are a contributing factor that have a significant effect on $\mathrm{L}_{\mathrm{av}}, \mathrm{U}_{\mathrm{o}}, \mathrm{TI}$, and SLEEC values. If the road lighting provides the low SLEEC value, it will make worth of energy use by comparing with the light generated from roadway lighting systems. When the road surfaces are wet, the average luminance coefficient $\mathrm{Q}_{0}$ and the specular factor change so much. For this reason, the road lighting systems have better $\mathrm{L}_{\mathrm{av}}$ and SLEEC values, but there are adverse effects on the lighting quality due to the high specular factor $\mathrm{S} 1$ - reduction of the $\mathrm{U}_{\mathrm{o}}$ value. In addition, using HPS luminaires in both dry and wet road surfaces cases higher $E_{a v}$ and $L_{a v}$ values than the LED luminaires. However, using LED luminaires can provide better $\mathrm{U}_{\mathrm{o}}$ and SLEEC values.

The authors wish to gratefully acknowledge financial support for this research from The Royal Golden Jubilee (RGJ) Ph.D. Scholarship. (PHD/0171/2559), Thailand

\section{References}

1. A.J. Anarkooli, M.H. Hosseinlou, "Analysis of the injury severity of crashes by considering different lighting conditions on two-lane rural roads," Journal of Safety Research, Vol. 56, pp.57-65 (2016).

2. CIE Publication 144:2001, Road surfaces and road marking reflection characteristics (2001).

3. D. Schreuder, "A portable reflectometer for on the road measurements. Experiences from the Netherlands," CIE Int. Symp. Road surface photometric characteristics, p.4 (2008).

4. L. Moretti, G. Cantisani, P.D. Mascio, "Management of road tunnels: construction, maintenance and lighting costs," Tunn. Undergr. Space Technol. 51, 84-89 (2016).

5. D. Wang, A. Schacht, Z. Leng, C. Leng, J. Kollmann, M. Oeser, "Effects of material composition on mechanical and acoustic performance of poroelastic road surface (PERS)," Construction and Building Materials, Vol. 135, pp. 352-360 (2017).

6. D. Wang, P. Liu, H. Wang, A. Ueckermann, M. Oeser, "Modeling and testing of road surface aggregate wearing behaviour," Construction and Building Materials, Vol. 131, pp.129-137 (2017).

7. Department of Highways. 2010. the department of highways within the geographical boundary of Thailand. [ONLINE] Available at: http://www.doh.go.th/. [Accessed 13 January 2015].

8. C. Rodrigues, P.S. Almeida, G.M. Soares, J.M. Jorge, D.P. Pinto, H. Braga, A C, "An experimental comparison between different technologies arising for public lighting: LED luminaires replacing high pressure sodium lamps," 2011 IEEE International Symposium on Industrial Electronics (ISIE), pp.141146 (2011).

9. A. Sędziwy, A. Basiura. "Energy Reduction in Roadway Lighting Achieved with Novel Design Approach and LEDs," LEUKOS, pp.1-7 (2017).

10. CIE Publication 66:1984, Road surfaces and lighting; joint technical report CIE/PIARC (1984)

11. CIE Publication 144:2001, Road surfaces and road marking reflection characteristics (2001)

12. CIE 31-1976 Glare and uniformity in road lighting installations (1976). 